\title{
Combined perceptual or motor-related expectancies modulated by type of cue
}

\author{
UWE MATTLER \\ Technische Universität Braunschweig, Braunschweig, Germany
}

\begin{abstract}
The interaction of two expectancies was examined. These were either two perceptual or two response-related expectancies. Perceptual expectancies were induced by combining spatial cuing with feature cuing on a trial-by-trial basis. Cues consisted either of two integrated parts, such as two arrows, or two separated pieces, such as an arrow and a word. Spatial-cuing effects were reduced on trials with invalid feature cues, as compared with valid ones. However, the interaction of spatial cuing and feature cuing was modulated by the type of cue used to induce expectancies. With integrated cues, spatial-cuing effects were reduced about twice as much as with separated cues. The same effect of type of cue was found in Experiment 2, although finger cuing was combined with hand cuing. With integrated cues, finger-cuing effects were much smaller on trials with invalid hand cues, as compared with valid ones. With separated cues, however, finger-cuing effects were additive to hand-cuing effects. The similarity of the results within perceptual-and motor-cuing tasks suggests that a general principle governs the combination of expectancies, such as that outlined in the framework of the proposed adjusted expectancy model.
\end{abstract}

Numerous studies have shown that performance can be improved when we have some knowledge of forthcoming events. In the domain of selective attention, much research on the effects of advance knowledge has focused on the spatial location of a visual target stimulus. In a typical spatial-cuing task, advance knowledge of the likely spatial location of the target stimulus is given by a precue. The common finding has been that on valid trials, on which the target appears at the cued location, reaction time (RT) is reduced, and response accuracy is increased. On invalid trials, on which the target appears at an uncued location, RT is prolonged, and accuracy is reduced (e.g., Posner, Snyder, \& Davidson, 1980). Similar effects of precues have also been demonstrated for cues regarding stimulus color (e.g., Humphreys, 1981), form (e.g., Posner \& Snyder, 1975), feature (e.g., Neely, 1977), or modality (e.g., Spence \& Driver, 1997). Interestingly, in the domain of movement control, similar cuing effects have been reported (e.g., Rosenbaum, 1980; Rosenbaum \& Kornblum, 1982). Advance knowledge about the motor response that will probably be required improves performance on valid trials, but it impairs performance on invalid trials.

In the present study, attentional- and response-cuing effects were examined and compared. To this end, com-

I thank Konstanze Fendrich and Hannes Schröter for helping in data collection, Armin Heinecke and Jens Schwarzbach for helpful discussions, and Dirk Vorberg for supportive comments throughout the work and on an earlier draft of the manuscript. Correspondence concerning this article should be addressed to U. Mattler, Fakultät für Naturwissenschaften, Institut für Psychologie II, Otto-von-Guericke Universität Magdeburg, Postfach 4120, D-39016 Magdeburg, Germany (e-mail: uwe.mattler@nat.uni-magdeburg.de). bined expectancy effects were analyzed in two experiments that combined either two perceptual expectancies or two response-related expectancies. ${ }^{1}$ By this means, in the present study, a first step toward a unification of perceptualand motor-cuing research was attempted by directly comparing perceptual and motor cuing in two experiments on combined expectancies. The results demonstrated a surprising similarity between perceptual and motor cuing, suggesting a unification of perceptual- and motor-cuing research.

In the following, findings regarding combined expectancies will first be briefly reviewed. Then I will report new results from Experiment 1 on the cuing of two aspects of selective visual attention. Here, the focus is on the combination of spatial cuing and stimulus feature cuing. After this, I will present the results from a comparable Experiment 2, in which response hand cuing was combined with response finger cuing. To anticipate my results, I found surprisingly similar effects of combined expectancies in the two experiments, despite considerable differences with respect to the content of the expectancies, their theoretical framework, and the presumed neurophysiological correlates of the effects. The results suggest that perceptual- as well as motor-cuing effects are governed by the same mechanisms as those specified explicitly by the adjusted expectancy model.

\section{Combined Expectancies}

Expectancy interaction. Within selective visual attention research, limits of spatial cuing have been revealed when spatial expectancies were combined with other expectancies. A series of studies has demonstrated that the effect of a spatial cue is larger when some other ex- 
pectancy is confirmed, as compared with when some other expectancy is disconfirmed (Kingstone, 1992; Kingstone \& Klein, 1991; Klein \& Hansen, 1987, 1990; Lambert, 1987; Lambert \& Hockey, 1986). For instance, Klein and colleagues (Klein, 1980; Klein \& Hansen, 1987,1990 ) combined spatial cuing with advance knowledge of the target stimulus by presenting one target more frequently than its alternative. Because participants responded to the identity of the target stimulus, the more frequent stimulus was confounded with the more frequent response. Normal spatial-cuing effects were observed for the frequent stimulus/response, with faster responses on valid trials and slower responses on invalid trials. However, spatial-cuing effects were absent for the infrequent stimulus/response: RT was about as long on valid trials as on invalid trials.

This elimination of spatial-cuing effects has been interpreted as evidence for spotlight failure by Klein and Hansen (1987). According to this view, visual attention does not always improve early visual processing, contrary to the hypothesis that attention operates like a spotlight (Posner et al., 1980) or like a zoom lens (Eriksen \& Yeh, 1985). However, the results are consistent with the alternative perspective that those spatial-cuing effects that are located at early levels of visual processing do not depend on other expectancies. According to this alternative view, the findings of Klein and colleagues suggest that spatial-cuing effects on early perceptual processing do not appear in performance measures because later processes produce the unexpected response. This alternative perspective has been coined spotlight masking by Klein and Hansen (1990), indicating that attentional spotlight effects are made invisible by later processes.

Interestingly, combined expectancies interact not only when spatial expectancies are combined with stimulusand response-related expectancies, but also when expectancies regarding stimulus form are combined with temporal (target appears early or late) or color-related expectancies (Kingstone, 1992). To account for these effects, Kingstone (1992) suggested that expectancy effects are modulated by crosstalk between coding systems. According to the crosstalk hypothesis, expectancies regarding later levels of processing (e.g., form) are adjusted when expectancies regarding early levels of processing (e.g., location) are disconfirmed. This view is consistent with the spotlight-masking hypothesis, because it assumes that spatial-cuing effects from early levels of processing can disappear in performance measures because of the effects of expectancies regarding later levels of processing. The crosstalk hypothesis differs from spotlight masking, however, because it is restricted to crosstalk between sensory coding systems, whereas spotlight masking assumes effects at the level of motor processing.

Recent research has shown that combined expectancies interact not only when spatial cuing is combined with response cuing, but also when modality cuing is combined with response cuing (Mattler, in press). This broad range of similar findings has been termed expectancy interaction by Mattler (in press), to indicate that this rather general phenomenon is not limited to spatial-cuing effects. To account for this broad rage of similar findings, Mattler (in press) combined and extended both the spotlightmasking idea and the crosstalk hypothesis and suggested an adjusted expectancy model. According to this view, expectancy effects located at later levels of processing can be adjusted on line if expectancies related to processing at earlier levels are disconfirmed. The model differs from both the crosstalk hypothesis and spotlight masking because it is more general, including any two levels of processing that occur in temporal sequence with respect to each other. Furthermore, the model makes the consequences of crosstalk between early and late levels of processing explicit in terms of a mathematical description of the time course of the activation of representations.

More specifically, to account for the interaction of two combined expectancies, the adjusted expectancy model assumes one instance of central control processes and two instances of peripheral data-processing units (see Posner \& Raichle, 1994). Central processes (working memory) interpret the cues and control their effects on data-processing units. Data-processing units consist of competitive networks of representations that represent possible events. Whereas central processes may be shared by different tasks, the data-processing units are assumed to differ anatomically with the particular events that are expected. With respect to cuing effects, however, the model assumes that data-processing units operate in the same way regardless of other functional and anatomical differences. The model assumes a sequential structure of data-processing units, with one expectancy effect located at an early level and another expectancy effect located at a later level of data processing. The effect of expectancy is implemented in the model by the activation of data-processing units prior to and during target processing. For instance, a spatial cue causes the activation of the spatial representation of that location where the target is expected. This activation leads to faster spatial processing on valid trials but to slower spatial processing on invalid trials, on which the target has to be processed by representations that compete with the cued representation. When two expectancies are combined, two representations are activated prior to target processing. Because each expectancy refers to a different network of representations (e.g., a spatial representation vs. a motor representation), each activated representation competes with a different, alternative representation (e.g., upper against lower visual field vs. left- against righthand response). The activation of representations at late levels of processing can be changed on line during target processing as a function of confirmation of the expectancy at lower levels of processing. For instance, if spatial processing confirms the spatial expectancy in a given trial, central processes receive a confirmatory signal, causing an increase of the activation that was indicated by the response cue on this trial. Therefore, response-cuing ef- 
fects are increased on trials with valid spatial cues, as compared with trials with no spatial cue, leading to faster responses on trials with valid response cues but slower responses on trials with invalid response cues. On the other hand, if spatial processing disconfirms the spatial expectancy because the target appeared at an uncued location, central processes receive a disconfirmation signal, causing a decrease of the activation indicated by the response cue. Therefore, response-cuing effects are reduced on trials with invalid spatial cues, as compared with trials with no spatial cue, with relatively slow responses on trials with valid response cues and relatively fast responses on trials with invalid response cues. In this way, the adjusted expectancy model accounts for the expectancy interaction usually found with combined expectancies.

Modulation of expectancy interaction. In certain circumstances, combined expectancies produce additive effects (Kingstone, 1992; Lambert \& Hockey, 1986; Mattler, in press). Several factors have been put forward as causes of additive expectancy effects. (1) On the basis of findings from two experiments, Kingstone proposed that the presence of a distractor stimulus leads to additive effects of spatial cuing and target form cuing. However, this view was not supported by the results of the recent experiments of Mattler (in press), which showed expectancy interaction despite the presence of a distractor. (2) Kingstone suggested that low cue validity might reduce expectancy interaction, because effects were reduced in one of Kingstone's and one of Lambert and Hockey's (1986, Experiment 1) experiments. However, the results of both of these experiments can be questioned for methodological reasons. Kingstone examined the effect of cue validity by comparing $70 \%$ with $90 \%$ validity in a repeated measures design with very small numbers of replications in invalid conditions, and the relevant interaction with cue validity was not significant when the full design was analyzed. Lambert and Hockey used cues with $66 \%$ validity and found additive effects of expectancies when median RTs were analyzed. However, analysis of median RT possibly eliminated a true interaction, because sample medians tend to overestimate population medians when samples are small, as in conditions with invalid cues (Miller, 1988). Thus, given the background of a reliable expectancy interaction with a cue validity of $75 \%$ in previous experiments (Mattler, in press), the effect of cue validity remains at least unclear. (3) Klein (1994) and Murphy and Klein (1998) combined spatial cuing with stimulus-response combinations of different frequencies and found reduced interactions of cuing effects when the target location was cued by an exogenous cue that was presented at the spatial location of the target stimulus. This finding is consistent with other evidence showing that exogenous cuing effects differ from endogenous cuing effects (e.g., Briand \& Klein, 1987; Klein, 2000). However, a recent study by Milán and Tornay (2001) showed expectancy interaction with exogenous cues, indicating that exogenous cuing is not a sufficient condition for additive expectancy effects. Thus, at the present time, neither of these factors seems to be an entirely convincing cause of additive expectancy effects.

Type of cue. Another modulator of expectancy interaction has been studied in previous experiments and in the present two experiments-namely, type of cue. In a series of experiments, Mattler (in press) employed endogenous cues and found expectancy interaction with integrated cues but additive expectancy effects with separated cues. In one experiment, integrated cues consisted of two adjacent arrows: one indicating the likely target location and the other the likely response. In another experiment, integrated cues consisted of a single word indicating both the likely stimulus modality and the likely response. In contrast, separated cues consisted of an arrow indicating the likely target location and a word for the likely response. In another experiment, separated cues consisted of an arrow indicating the likely response and a word indicating either the likely cognitive task or the likely target object. In all of these experiments, expectancy interaction was found when integrated cues were used, but the interaction was virtually absent with separated cues.

Why should type of cue modulate expectancy interactions? Separated cues, consisting of a combination of an arrow and a word, differ in several regards from integrated cues, such as double arrows or single-word cues carrying two pieces of information. Separated cues consist of two clearly separated parts that have different formats, and they do not lead to a single integrated perceptual image. According to the present view, each part of separated cues provides knowledge of a likely event (stimulus or required response), and the fact that cues are separated provides the additional information that the two expectancies are not related to each other. To the contrary, integrated cues consist of two parts that are physically linked together into a single unit. Therefore, integrated cues provide the additional information that the expectancies are related to each other. Thus, according to the present view, expectancy effects interact if the cues implicitly suggest that the expectancies are related to each other, but expectancy effects remain largely independent if the cues implicitly suggest that the expectancies are not related to each other.

In terms of the adjusted expectancy model, adjustment of expectancies at later levels of processing is governed by implicit information provided by cues regarding the relation between early and late levels of processing. For integrated cues, the model assumes that confirmatory signals are used to change activations at late levels of processing, leading to expectancy interaction. For separated cues, however, the model assumes that expectancy effects on late levels of processing are not affected by processing at early levels. In other words, because separated cues implicitly suggest that the early-level expectancy is unrelated to the late-level expectancy, confirmatory signals from processing at early levels are not used to adjust activations at later levels of processing. Therefore, the effect of a late-level expectancy remains 
the same on trials with confirmed or disconfirmed earlylevel expectancies. In other words, the model predicts additive effects of combined expectancies when cues implicitly suggest that expectancies are unrelated.

\section{Objectives of the Present Research}

The present study had two objectives. (1) Previous experiments (Mattler, in press) had shown that the interaction of response cuing and perceptual cuing depends on type of cue. The present study explored whether crosstalk within perceptual systems is similarly modulated by type of cue. (2) Previous studies had combined either different perceptual expectancies (Kingstone, 1992; Lambert, 1987; Lambert \& Hockey, 1986) or perceptually related expectancy with response-related expectancy (Klein, 1980; Klein \& Hansen, 1987, 1990; Mattler, in press). Experiment 2 went beyond these studies in that the combination of advance knowledge of the response hand and the response finger was examined. If crosstalk is restricted to combinations of perceptual expectancies or to combinations between perceptual and response-related expectancies, additive expectancy effects should occur within motor-related expectancies. However, if crosstalk exists between any combination of expectancies, as is assumed by the adjusted expectancy model, expectancy interaction should occur also within motor-related expectancies. Furthermore, type of cue should modulate the way different motor expectancies act together.

\section{Combining Perceptual Expectancies}

The allocation of attention to visual space is often studied within visual search paradigms. Experiment 1, which combines spatial cuing with feature cuing, may be regarded as a simplified variant of visual search tasks. In the visual search paradigm, arrays containing multiple stimuli are presented, and the task is to report whether a target stimulus is part of the array. Search time for the target usually increases with the total number of stimuli in the array. According to a common view, this results from a serial search process that examines one stimulus at a time until the target is found. However, under some conditions, the time needed to detect the target is roughly independent of the number of stimuli in the array, suggesting that the elements are searched in a parallel fashion.

The large number of findings regarding the conditions for serial and parallel search has motivated elaborated models that have followed the feature integration theory of Treisman and Gelade (1980; Found \& Müller, 1996; Treisman \& Sato, 1990; Wolfe, 1996; Wolfe, Cave, \& Franzen, 1989; for a review and alternative models, see Wolfe, 1998). Several of these models implement parallel search at an early preattentive level of processing, where simple features, such as color or orientation, are processed in parallel across space in separate feature modules. Serial search is implemented at a later level of processing, where features with the same spatial location are bound into objects by a process that requires focused attention. For instance, according to the guided search model of Wolfe et al. (1989; for the revised Version 2.0, see Wolfe, 1994), individual target features are processed in parallel across the entire visual field by comparing single objects with their neighbors. At a second stage, the spatial distribution of differences between neighbors is represented. At this stage, visual attention visits one location with high activation after the other. This bottom-up effect at the second stage leads to efficient search when a salient feature target is present in the display. In addition, the search process can be guided top down by weighting the effect of features at the second stage, where conjunctions of single features are bound together by the visiting focus of attention.

What could be expected for the combination of feature cuing and spatial cuing in the context of visual search models? On the one hand, top-down effects of feature cues could enhance the activity of feature maps, and spatial cues could guide the spotlight of attention at the second stage. Because feature cues and spatial cues affect different stages of processing, we might expect additive cuing effects. However, activation of feature maps guides the focus of attention to the location of high activation on the activation map. Thus, the feature cue has also an indirect effect on the activation map. By this means, both cues affect the same stage of processing, which should result in an interaction of feature cuing and spatial cuing. In this context, however, type of cue should not have any modulating effect on expectancy interaction. In contrast to this prediction, combined expectancy effects have depended on type of cue when spatial cuing has been combined with response cuing, with larger interactions resulting from integrated cues, as compared with separated cues (Mattler, in press). Therefore, it was predicted that type of cue also modulates the interaction of spatial cuing and feature cuing. ${ }^{2}$

\section{EXPERIMENT 1 Spatial Cuing and Feature Cuing}

Experiment 1 was intended to determine how spatial cuing and target feature cuing combine and whether the combination depends on what type of cue is used. Participants responded to vertical color bars and tilted white bars, presented either above or below fixation. Information regarding the target feature (color vs. orientation) was given by a single word. Target location was cued either by an arrow (separated cues) or by the position of the word cue (integrated cues). If expectancy interaction depends on response-related expectancies, type of cue should have no effect. However, if the interaction of expectancies follows the same rules with any combination of expectancies, type of cue should modulate the extent of the expectancy interaction, leading to a larger interaction with integrated cues, as compared with separated cues.

\section{Method}

\section{Participants}

Two groups of 20 students from the University of Braunschweig participated in the experiment (16 women and 4 men in Group 1, 17 
women and 3 men in Group 2; their ages ranged from 19 to 41 years $(M=23.7$ and 24.0 years, respectively). All but 3 participants in the first group reported being right-handed. All had normal or correctedto-normal vision, and none reported having problems with color discrimination. All were naive as to the purposes of the experiment, and none had participated before in a similar experiment. Each participant took part in two 1-h sessions, receiving course credit for participation.

\section{Task}

The participants responded to the color or the tilt of a target bar, presented together with a distractor bar, by pressing a response key on the keyboard with the index finger of the left or right hand. Precues presented before the stimuli indicated the likely stimulus feature of the target and/or the likely spatial location of the target.

\section{Stimuli}

Stimuli were presented as light-on-black images. Possible target locations were indicated by two square frames located $4.8^{\circ}$ of visual angle (edge to edge) above or below the fixation plus sign in the center of the monitor (see Figure 1). The fixation cross subtended $0.2^{\circ}$; squares subtended $1.3^{\circ} \times 1.3^{\circ}$ of visual angle. On each trial, one of the squares contained a target stimulus, and the other contained a distractor stimulus. Target and distractor stimuli consisted of bars subtending about $0.9^{\circ}$ of visual angle. In the target set, the color targets were vertical, either in red or in green, whereas the tilted targets were white, tilted either to the right or to the left by $5.4^{\circ}$. In the distractor set, the color distractors were yellow or pink, and the tilted distractors were white bars tilted by $44^{\circ}$. On each trial, one colored stimulus was presented together with one tilted stimulus; one stimulus was from the target set, and the other was from the distractor set. Each distractor was combined with each target with equal frequency.

Feature cues were the German words Farben, Winkel, and Beides (English, colors, angle, and both). The words subtended about $1.3^{\circ}$ of visual angle. On trials with valid feature cues, the cued dimension of the target stimulus was mapped to a response. On trials with invalid feature cues, the cued dimension was virtually absent in the target stimulus, because a white tilted bar followed the colors cue and a nontilted vertical bar in green or red followed the angle cue. In one group of participants (separated cues), the word always appeared at the fixation point, and spatial cues were made of arrows pointing up or down to a target field (see Figure 2). Arrows subtended $0.9^{\circ}$ of visual angle. Neutral spatial cues were made by a combination of both arrows. In the other group of participants (integrated cues), advance knowledge of the likely target location was given by placing the word cue $0.5^{\circ}$ of visual angle above or below fixation. Error feedback was given by a $1000-\mathrm{Hz}$ tone with a 50-msec duration.

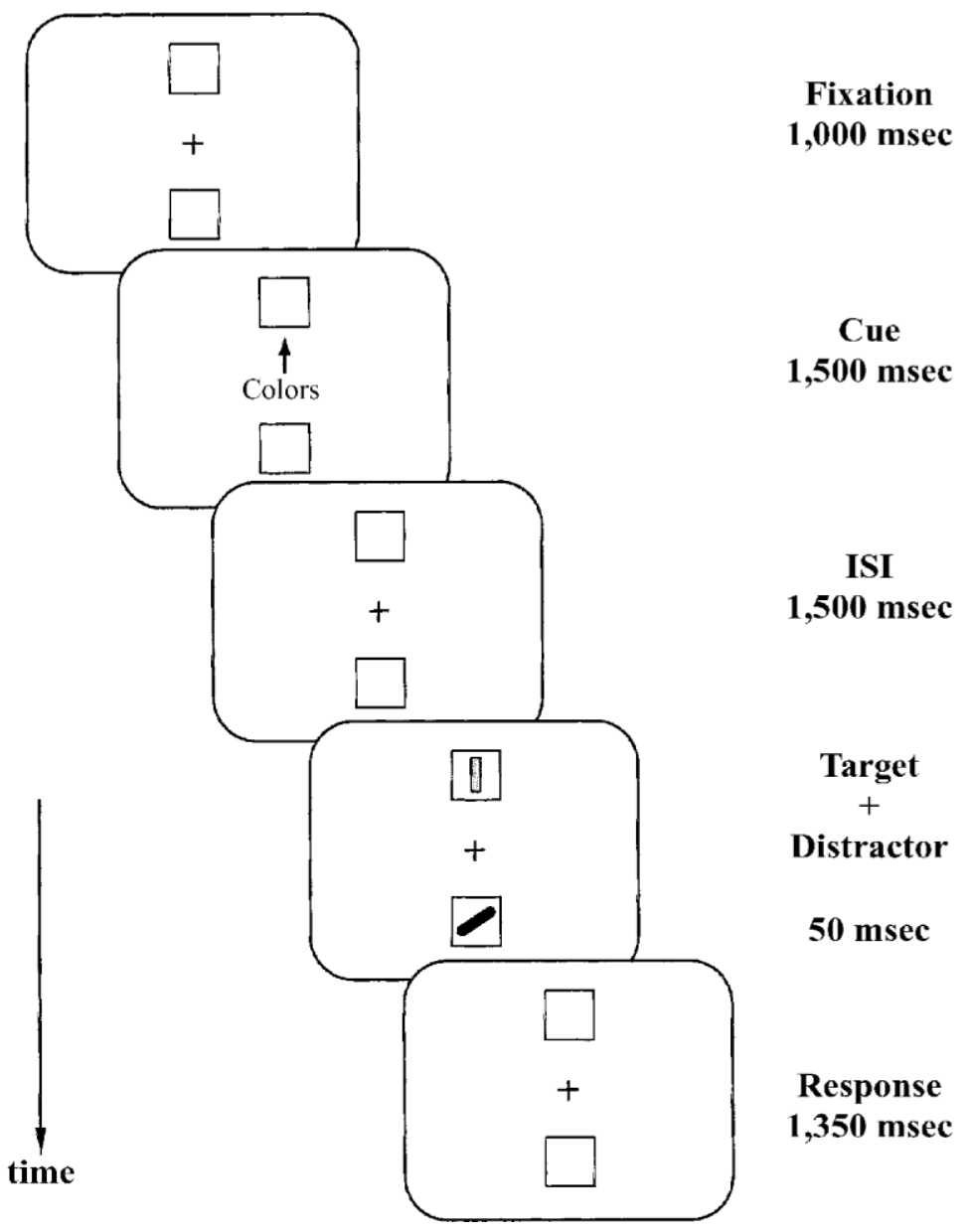

Figure 1. Schematic diagram of the sequence of events in Experiment 1. In this example of a trial with valid spatial and valid feature cuing, type of cue is arrow-and-word. ISI, interstimulus interval. 
Separated Cues

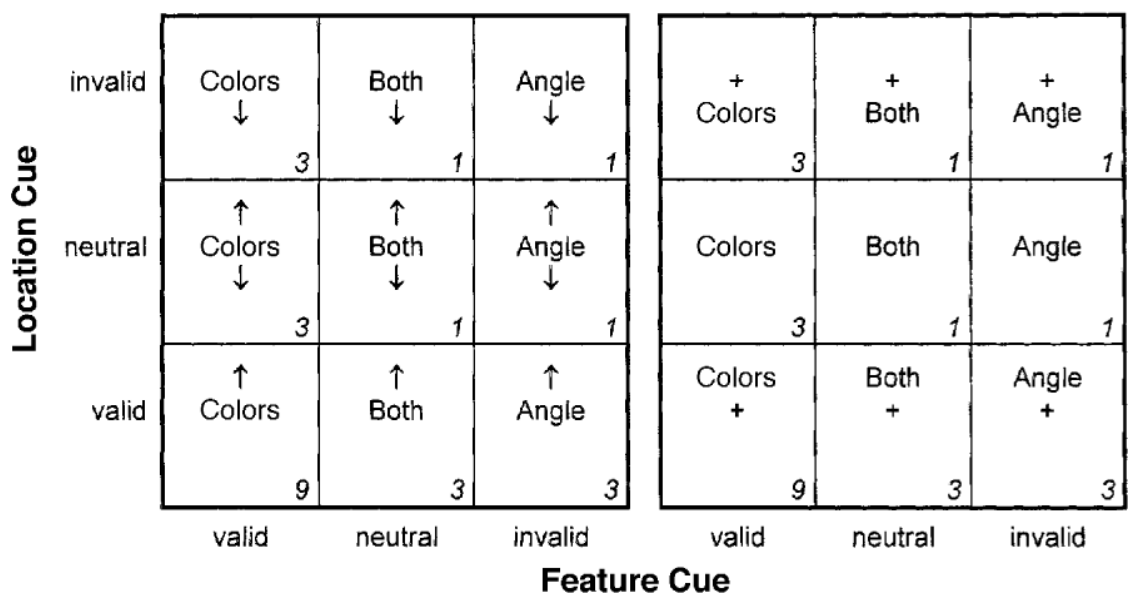

Figure 2. Combination of advance knowledge of target location and target feature in Experiment 1. Cues were either separated or integrated. For each target stimulus, nine possible combinations of valid, neutral, and invalid information regarding target location and target feature were given with unequal frequencies. Cues correspond to the example of a color target stimulus located above fixation; numbers indicate the frequency of each combination. Word cues are given as the English translation of the German words used.

\section{Design}

A mixed design was used, with type of cue as a between-subjects factor (integrated vs. separated) and with two within-subjects factors, spatial cue and feature cue, each varying on three levels (valid, neutral, and invalid), resulting in a $3 \times 3$ repeated measures design within each group. Dependent measures were RT and percentage of errors. Each spatial cue was combined with each feature cue. Each cue was valid in $75 \%$ of the trials. Cue validity was realized by having more trials with valid cues than trials with neutral and invalid cues. As an example, Figure 2 gives the frequency of each of the nine cue combinations for a color target located above fixation. Each target was preceded by each cue combination. After some practice, two blocks of 200 trials followed in each of the two sessions, comprising 32 replications in each of the four most infrequent conditions. In the last session, a block with only valid cues followed, the data of which will not be reported here.

\section{Procedure}

The participants were tested individually in single sessions on separate days. They sat in a silent, sparsely illuminated room and viewed the computer monitor from a fixed chinrest. The participants were informed about the validity of both aspects of the cue. They were instructed to keep their eyes on the fixation cross throughout the trial, to attend to and use the cues, and to respond to the target stimulus as quickly as possible without making too many errors. The sequence of events is given in Figure 1. Trials started with the fixation signal, followed, after $1,000 \mathrm{msec}$, by cues for $1,500 \mathrm{msec}$. After another 1,500 msec of fixation, the target and the distractor stimulus followed for $50 \mathrm{msec}$. Responses were given by pressing the "Y" or the "-" button on the computer keyboard with the left or the right index finger, respectively. (These keys are located on the German keyboard just above the ALT and ALT Gr keys.) The computer monitored for a response within $1,400 \mathrm{msec}$ after target onset. In the case of a wrong response, feedback was given after this period, followed by a rest of 2,000 msec. The next trial started after $1,000 \mathrm{msec}$.
To interpret spatial-cuing effects in terms of covered shifts of attention, it is important to exclude the possibility that the cuing effect results from overt eye movements, because faster responses on trials with valid spatial cues, as well as slower responses on trials with invalid cues, might result as well from eye movements to the cued location. To eliminate eye movements from the present experiment, three techniques were used. First, the participants were instructed to keep their eyes on the fixation point. Second, the participants were asked, in the interview after each session, whether they could keep eyes on fixation, and every participant that could not follow this instruction was replaced by another participant. Third, stimulus presentation time was $50 \mathrm{msec}$, to punish any eye movement by minimizing chances to see the stimuli at the alternative location on trials with invalid spatial cues. By this means, the error rate on trials with invalid spatial cues provides an indirect measure of the frequency of eye movements. Given that the participants had to guess the target on trials with invalid spatial cues if they made an eye movement to the cued spatial location, we would expect one out of four correct guesses. Therefore, similar error rates of below $20 \%$ on trials with invalid feature cues, as well as on trials with invalid spatial cues, suggest that eye movements were relatively rare.

\section{Statistical Analysis}

Choice RTs were summarized by means, determined for correct trials per participant and condition, excluding posterror trials (Rabbitt, 1966). Initially, RT and arc-sine transformed error rates were analyzed separately for each group with two $3 \times 3$ repeated measures analyses of variance (ANOVAs) with factors of spatial cue and feature cue. Then groups were compared in an extended ANOVA with a between-subjects factor of type of cue and the two repeated measures factors. Note that factors such as response hand (left or right), target stimuli (red or green and left or right tilted), and target location (above or below fixation) varied orthogonally within the $3 \times 3$ design and that the data were pooled across these factors to increase the reliability of performance estimates in con- 
ditions with small numbers of trials. The analysis was restricted to the three relevant factors of the experiment. All reported $p$ values were based on Geisser-Greenhouse corrected degrees of freedom, whereas, for the sake of readability, the stated degrees of freedom were uncorrected.

\section{Results}

\section{Separated Cues}

RT. The effect of feature cue was significant, with means of 647, 685, and $739 \mathrm{msec}$ for valid, neutral, and invalid feature cues, respectively $\left[F(2,38)=47.2, M S_{\mathrm{e}}=\right.$ $2,744, p<.001]$. Spatial cue had a significant effect on RT, with means of 636,683 , and 752 msec for valid, neu- tral, and invalid spatial cues, respectively $[F(2,38)=$ $\left.97.3, M S_{\mathrm{e}}=2,080, p<.001\right]$. As compared with the neutral cue conditions, both feature cue and spatial cue produced significant costs and benefits $(p<.05)$. The interaction of feature cue and spatial cue reached significance $\left[F(4,76)=7.0, M S_{\mathrm{e}}=780, p=.001\right]$. To see whether the interaction results only from the neutral cue conditions, an analysis without trials from neutral cue conditions was conducted, which confirmed the former analysis, including the significant interaction $[F(1,19)=12.7$, $\left.M S_{\mathrm{e}}=1,031, p=.002\right]$. Means for each of the nine combinations of feature cue and spatial cue are given in Figure $3 \mathrm{~A}$.
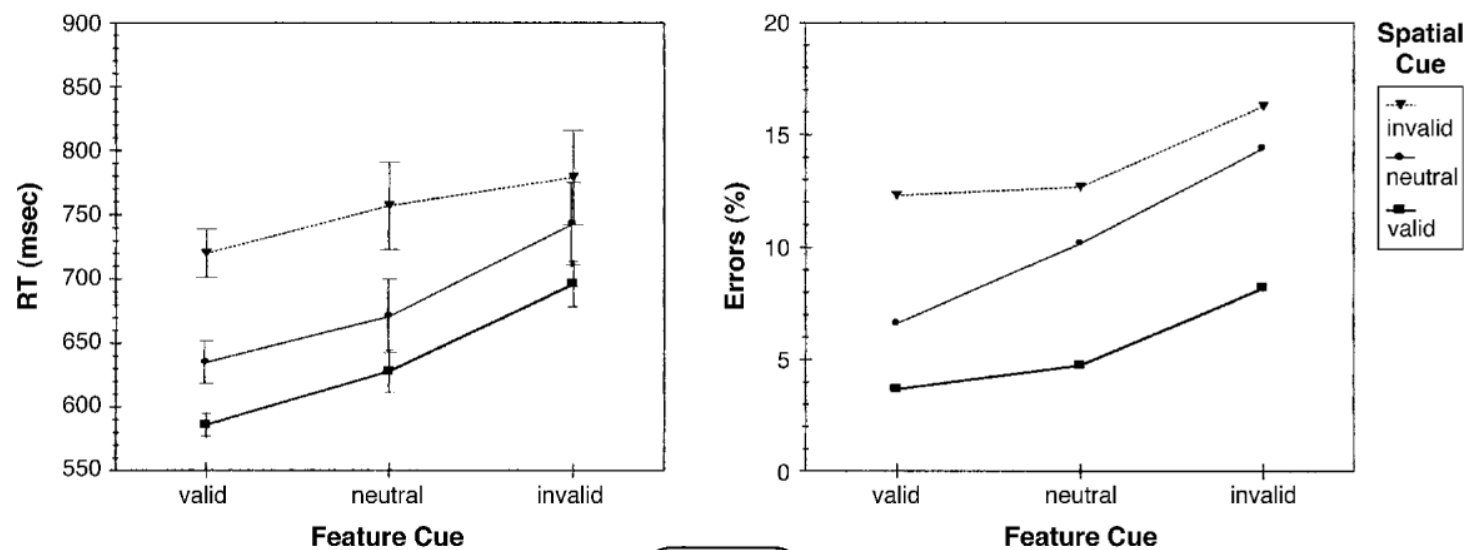

B

Colors

$+$
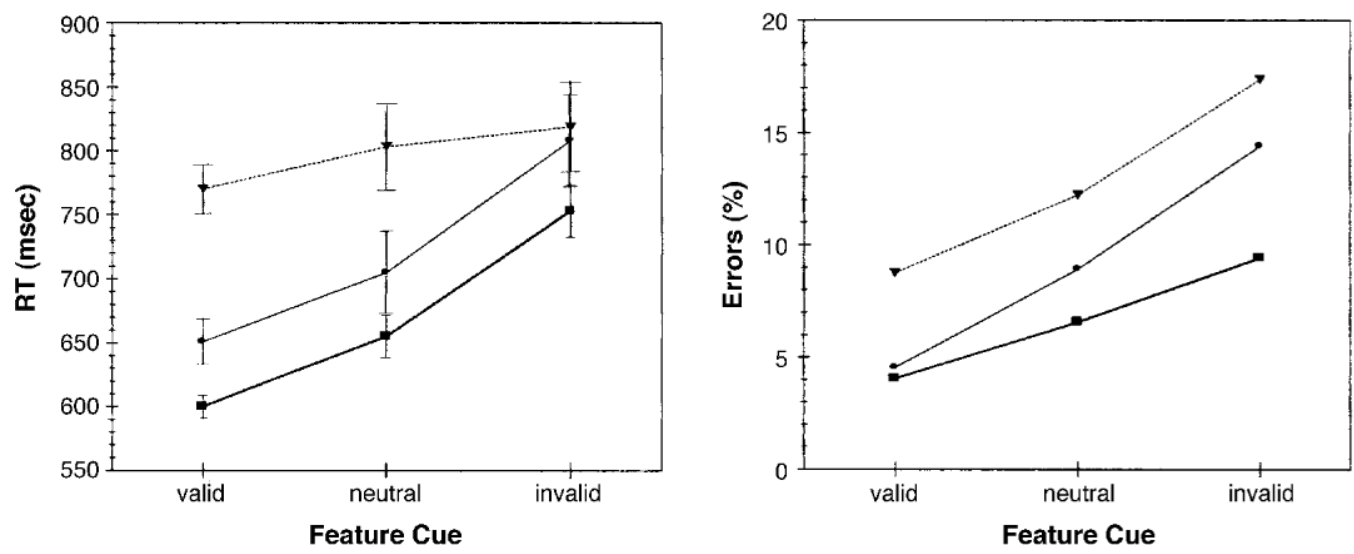

$\begin{aligned} & \text { Spatial } \\
& \text { Cue }\end{aligned}$
\begin{tabular}{|l|}
\hline \multirow{2}{*}{ invalid } \\
neutral \\
\hline valid \\
\hline
\end{tabular}

Figure 3. Reaction times (RTs) and error rates of combined expectancies of target location and target feature in Experiment 1. (A) Data of the group with separated cues. (B) Data of the group with integrated cues. Examples of type of cue are given in the monitor sketch between the left and the right panels. Error bars show twice the mean standard error of RTs of single trials for each condition, calculated for each participant and averaged across participants. 
Errors. Errors occurred on $9.9 \%$ of the trials. Mean error rates were significantly affected by feature cue, with mean errors of $7.5 \%, 9.2 \%$, and $12.9 \%$ for valid, neutral, and invalid feature cues, respectively $[F(2,38)=$ $\left.15.8, M S_{\mathrm{e}}=0.033, p<.001\right]$. Spatial cue had a significant effect on error rate, with mean errors of $5.5 \%$, $10.4 \%$, and $13.7 \%$ for valid, neutral, and invalid spatial cues, respectively $\left[F(2,38)=26.4, M S_{\mathrm{e}}=0.041, p<\right.$ $.001]$. As compared with the neutral cue conditions, both feature cue and spatial cue produced significant costs, but only spatial cue produced significant benefits $(p<$ $.05)$. The interaction of feature cue and spatial cue was not significant $[F(4,76)=2.2, p=.09]$. Mean error rates are given in Figure 3A.

\section{Integrated Cues}

RT. The effect of feature cue was significant, with means of 674,721 , and $793 \mathrm{msec}$ for valid, neutral, and invalid feature cues, respectively $\left[F(2,38)=83.1, M S_{\mathrm{e}}=\right.$ $2,612, p<.001]$. Similarly, spatial cue had a significant effect on RT, with means of 669, 721, and 797 msec for valid, neutral, and invalid spatial cues, respectively $\left[F(2,38)=40.2, M S_{\mathrm{e}}=6,202, p<.001\right]$. As compared with the neutral cue conditions, both feature cue and spatial cue produced significant costs and benefits $(p<$ $.05)$. The interaction of feature cue and spatial cue was significant $\left[F(4,76)=22.2, M S_{\mathrm{e}}=946, p<.001\right]$. To see whether the interaction results only from neutral cue conditions, an analysis without trials from the neutral cue conditions was conducted, which confirmed the former analysis, including the significant interaction $\left[F(1,19)=64.9, M S_{\mathrm{e}}=839, p<.001\right]$. Mean RTs are given in Figure $3 \mathrm{~B}$.

Errors. Incorrect responses occurred on $9.6 \%$ of the trials. Mean error rates were significantly affected by feature cue, with mean errors of 5.8\%, 9.2\%, and $13.7 \%$ for valid, neutral, and invalid feature cues, respectively $\left[F(2,38)=19.4, M S_{\mathrm{e}}=0.050, p<.001\right]$. Spatial cue had a significant effect on error rate, with mean errors of $6.7 \%, 9.3 \%$, and $12.8 \%$ for valid, neutral, and invalid feature cues, respectively $\left[F(2,38)=26.7, M S_{\mathrm{e}}=0.026, p<\right.$ $.001]$. As compared with the neutral cue conditions, feature cue and spatial cue produced significant costs and benefits $(p<.05)$. However, the interaction of feature cue and spatial cue failed to reach significance $[F(4,76)=$ $1.3, p=.28]$. Mean error rates are given in Figure 3B.

\section{Comparing Groups With Different Types of Cues}

RT. Across experiments, the effect of feature cue and the effect of spatial cue were significant $[F(2,76)=127$, $M S_{\mathrm{e}}=2,678, p<.001$, and $F(2,76)=109, M S_{\mathrm{e}}=4,141$, $p<.001$, respectively]. The interaction of feature cue and spatial cue was significant too $[F(4,152)=27.5$, $\left.M S_{\mathrm{e}}=863, p<.001\right]$. Most important, the interaction of type of cue, feature cue, and spatial cue was significant $\left[F(4,152)=3.1, M S_{\mathrm{e}}=863, p=.03\right]$. This interaction was not due to neutral cue conditions, because the analysis without the data from the neutral trials confirmed the interaction of type of cue, feature cue, and spatial cue $\left[F(1,38)=7.6, M S_{\mathrm{e}}=935, p=.009\right]$. No other effect reached significance.

Errors. The analysis of both groups yielded a significant effect of both feature cue $\left[F(2,76)=34.7, M S_{\mathrm{e}}=\right.$ $0.041, p<.001]$ and spatial cue $[F(2,76)=51.6, p<$ $.001]$. The interaction of feature cue and spatial cue failed to reach significance $[F(4,152)=2.4, p=.06]$. Similarly, the interaction of type of cue, feature cue, and spatial cue was not significant $[F(4,152)=1.3, p=.29]$. No other effect reached significance.

Discussion. The combination of feature cuing with spatial cuing yielded significant effects of both feature cues and spatial cues on performance measures. Valid cues improved speed and accuracy, but invalid cues impaired performance in both groups of participants. ${ }^{3}$ In both groups, the effect of feature cue was reduced on trials with invalid spatial cues, and spatial-cuing effects were reduced on trials with invalid feature cues. However, this effect was much larger in the group with integrated cues, as compared with the group with separated cues (Figure 3B). With separated cues, spatial-cuing effects were reduced by $51 \mathrm{msec}(134 \mathrm{vs} .83 \mathrm{msec})$ on trials with invalid feature cues, as compared with valid feature cues, but spatial-cuing effects were reduced to $104 \mathrm{msec}$ (170 vs. $66 \mathrm{msec}$ ) with integrated cues. Thus, two perceptual expectancies affect each other to a greater extent when integrated cues are used, as compared with when separated cues are used. This modulation of combined expectancy effects by type of cue replicates previous findings (Mattler, in press).

The interaction of feature-related and location-related expectancies in conditions with integrated cues is in line with Kingstone's (1992) findings from the combination of spatial cuing and target form cuing. The present results show that spatial cuing combined with feature cuing is comparable to the combination of spatial cuing with cuing of feature conjunctions (Kingstone, 1992). Note, however, that Kingstone found no interaction of spatial cuing and target form cuing when the target was accompanied by a distractor, whereas expectancy interaction occurred when the target was presented without a distractor. Contrary to this, the present experiment showed interacting expectancies even though the target was accompanied by a distractor. This finding is in line with previous experiments showing that expectancy interaction does not depend on the presence of a distractor. This was found in the combination of modality cuing and response cuing, as well as in the combination of spatial cuing and response cuing (Mattler, in press). Finally, the present results show that reduced spatial-cuing effects do not depend on the processing of unexpected responses (e.g., Klein, 1980; Klein \& Hansen, 1987, 1990).

The finding of an interaction of spatial cuing and feature cuing is consistent with theories of visual search that assume that the spotlight of attention is guided by two factors-namely, the spatial cue and the location with 
high activation (e.g., Wolfe, 1996; Wolfe et al., 1989). The effect of type of cue, however, was not predicted from these visual search theories. Why is the interaction of expectancies larger with integrated than with separated cues? According to the present view, integrated cues implicitly provide the information that expectancies are linked together. Therefore, the system concludes, from the processing of one, invalid aspect of integrated cues, that the second aspect of the cue is invalid too in this trial, just as if it were reasoning something like "Since the feature cue was invalid, one should not trust in the spatial cue." Separated cues, however, implicitly suggest that the expectancies do not depend on each other. Therefore, the conclusion drawn by the system with respect to the validity of the expectancy at early levels is not applied to the validity of the expectancy at later levels of processing. In terms of the adjusted expectancy model, confirmation and disconfirmation of early-level expectancies triggers the on-line adjustment of expectancy effects at later levels of processing if the cues implicitly indicate that the expectancies are related to each other.

In the framework of visual search, the spotlight of attention is guided bottom up by the activation on feature maps and top down by spatial cuing. According to the present view, attention is affected (1) indirectly by an increase of the activation on feature maps due to the feature cue and (2) more directly by the spatial cue when separated cues are used. Therefore, combined cuing effects interact even with separated cues. With integrated cues, however, the effect of spatial cuing on the spotlight of attention is enhanced on trials with valid feature cues, because early feature processing has revealed that cues are valid, leading to an increase in the effect of the spatial cue. But spatial-cuing effects are reduced on trials with invalid feature cues, because the result of early feature processing leads to a decrease of the effect of the spatial cue. This on-line adjustment of the spatial-cuing effect leads to an enhanced interaction of feature cuing and spatial cuing.

\section{Combining Motor-Related Expectancies}

Whereas perceptual cuing affects the processing of stimulus input, motor cuing influences the processing of motor output. Traditionally, therefore, the first experiment refers to theories of visual selective attention, and the following, second experiment refers to theories of motor control. In comparing perceptual and motor cuing, the question is, Do two response-related expectancies combine according to the same rules as two perceptual expectancies? Are the effects of two response-related expectanciesindependent with separated cues, and do expectancies interact with integrated cues? To emphasize the difference between the second and the first experiments, I will first outline the theoretical framework for the second experiment. Then I will show that both experiments were designed along the same lines with respect to cuing and expectancy effects.
Motor cuing. The organization of the motor system has been studied with precuing paradigms (e.g., Rosenbaum, 1980; Rosenbaum \& Kornblum, 1982), in which a cue validly informs participants which particular responses out of a larger response set will be requested by a forthcoming imperative stimulus. Rosenbaum (1980) used this paradigm to examine the preparation of components of arm movements. The results showed that RT was prolonged the more movement components had to be specified after target presentation. Specification time for movement extent was longer than that for movement direction and was longest for which arm was used, suggesting a serial order of specification. Because any component given by precues facilitated RT, Rosenbaum concluded that the order of specification is variable (see Rosenbaum, 1980, 1983). Component specific preparation is supported by single-cell recordings in the motor cortex in monkeys that showed specific neuronal responses to different components of movements, such as distance or direction of a forthcoming movement (e.g., Fu, Flament, Coltz, \& Ebner, 1995; Requin, Riehle, \& Seal, 1993).

Variable order of specification, however, was questioned by some researchers (e.g., Miller, 1982; Ulrich, Giray, \& Schäffer, 1990). Miller (1982) found evidence against serial specification when pairs of responses of the index and the middle fingers of both hands were cued in a four-choice RT task. Hands were placed in a natural way, with fingers on four response keys that were assigned compatibly to four horizontal locations on the computer monitor. Precues were given by plus signs at two or four positions on the monitor. Response hand was cued by two plus signs above the two fingers of the left (or right) hand, and response finger was cued by two signs above the position of the two index (or middle) fingers of the left and right hands. The target was a single plus sign that followed at the location of one of the precues after a variable time interval. The results showed that only hand precues had an effect on RT, suggesting that the finger component of these movements cannot be specified unless it is clear which hand to use. In other words, order of specification was not variable (see Miller, 1985, 1987, 1988).

Reeve and Proctor $(1984,1985)$ questioned Miller's results because they found that the hand advantage effect depended on participants' strategy and disappeared when the time between the cue and the target was $3,000 \mathrm{msec}$. Furthermore, these authors showed that the hand effect depends on the location of response fingers, rather than depending on being part of the same hand. According to this, hand advantage effects result because spatial coding of the responding hand is usually more efficient than coding of the fingers.

Combined expectancies. Within this theoretical framework, the present paradigm provides an alternative approach by which to examine the interaction of hand and finger specification by using the cuing paradigm, which compares the effects of valid, neutral, and invalid 
cues. In Experiment 2, advance knowledge of the likely response hand was combined with advance knowledge of the likely finger. If the finger component cannot be specified before the hand component (as Miller's results suggest), the effect of finger cue should be reduced in trials with invalid hand cues, and expectancies should interact. However, if finger and hand components are specified in variable order (as are other movement components; Rosenbaum, 1983), the effect of finger cues should be the same with valid and invalid hand cues, and cuing effects should therefore be additive. In contrast to either of these predictions, finger cuing might be combined with hand cuing in the same way that spatial cuing is combined with feature cuing. Therefore, it is predicted that type of cue determines the interaction between finger cuing and hand cuing.

To allow for a direct comparison between experiments, Experiment 2 was designed along the same lines as Experiment 1 with respect to cues and expectancies (compare Figure 1 with Figure 4). First, Experiment 2 combined two response-related expectancies (finger and hand), just as Experiment 1 combined two perceptual expectancies (stimulus position and feature), applying valid, neutral, and invalid trials. Second, perceptual expectancies were held constant in Experiment 2, just as response-related expectancies were held constant in Experiment 1 . Third, in both experiments, integrated cues were used in one group of participants, whereas another group used separated cues. Fourth, the time for cue processing and development of expectancies was identical in both experiments. Differences resulted because different expectancies were studied in the two experiments: In Experiment 2, a single target letter was presented clearly in the center of the monitor in order to eliminate effects of visual spatial expectations. To distinguish hand and finger cuing, four alternative responses had to be used. To eliminate effects of expectancies related to stimulus form, two letters were mapped onto each of the four motor responses in Experiment 2. Taken together, task, target stimuli, and responses differed between ex-
Separated Cues

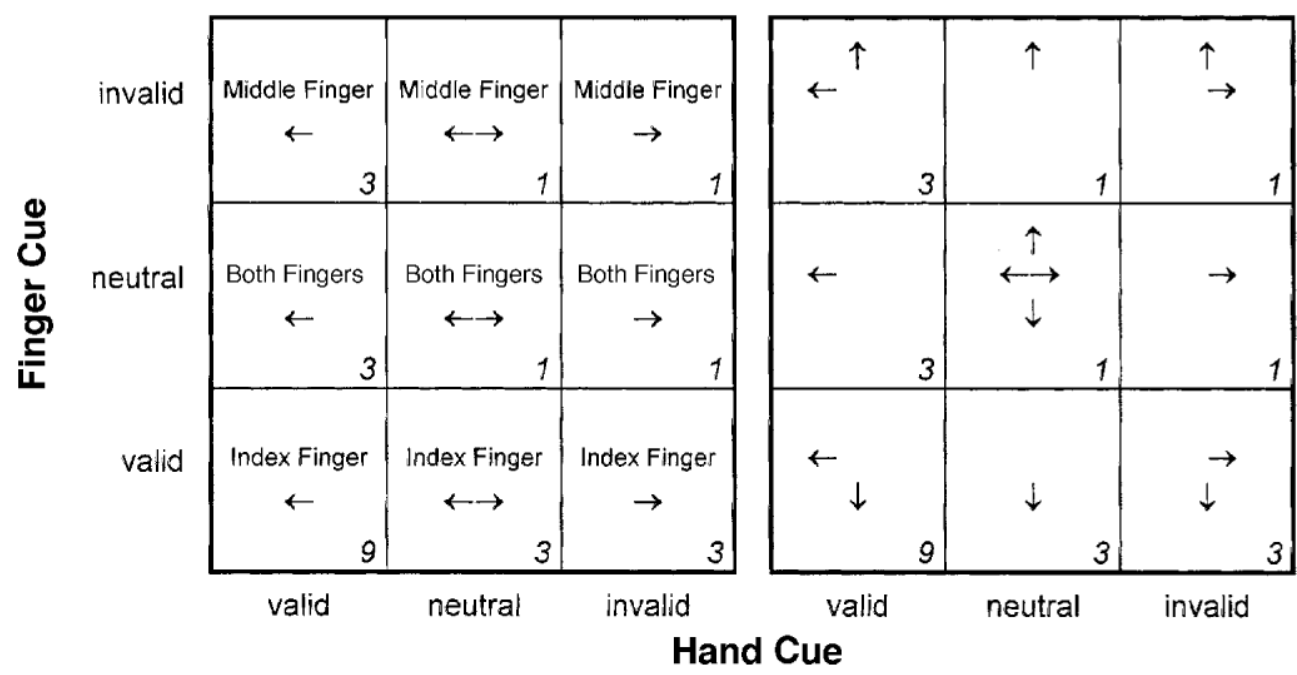

Response $=$ index finger of the left hand

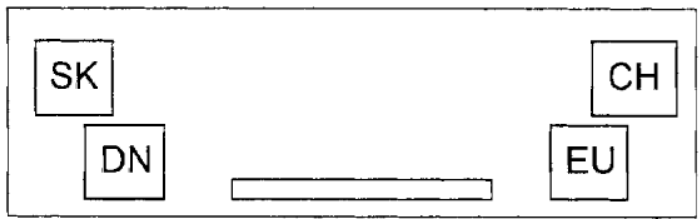

Figure 4. Combination of advance knowledge of response hand and response finger in Experiment 2. Upper panel: Cues were either separated, consisting of a word and an arrow, or integrated, consisting of two arrows. For each target stimulus, nine possible combinations of valid, neutral, and invalid information regarding finger and hand of the response were given with unequal frequencies. The cues presented correspond to the example of a response with the left index finger. Numbers indicate the frequency of each combination. Words are given as the English translation of the German words used. Lower panel: location of response keys on a covered computer keyboard. The upper row of response keys were mapped to middle fingers, the lower row to index fingers. Within each key, the target stimuli are shown here, but not in the experiment. 
periments, due to technical reasons. More important, however, the experiments were the same with respect to the combination of two expectancies in a trial-by-trial fashion, with identical frequencies of valid, neutral, and invalid trials, using separated and integrated cues in two groups of participants, with the same interstimulus interval between cue and target presentation in both experiments.

\section{EXPERIMENT 2 Hand Cuing and Finger Cuing}

Experiment 2 examined whether the effects of the combination of hand cuing and finger cuing depend on type of cue. The participants responded to clearly visible single-letter stimuli presented at fixation. Cues were either integrated, consisting of two arrows, or separated, consisting of an arrow and a word.

\section{Method}

\section{Participants}

Two groups of 10 students from the University of Braunschweig each participated in the experiment ( 9 women and 1 man, and 6 women and 4 men, respectively), with an age range from 20 to 41 years $(M=25.8$ and 27.6 years, respectively). All but 1 participant in each group reported being right-handed. All were naive as to the purposes of the experiment, and none had participated before in a similar experiment. Each participant took part in three 1-h sessions, receiving course credit for participation.

\section{Task}

In a four-alternative choice reaction task, the participants responded to visually presented letter stimuli by pressing one of four keys on the keyboard with the middle or index finger of the left or right hand. Precues presented before the target stimulus indicated the hand and/or the finger most likely involved in the response.

\section{Apparatus and Stimuli}

The participants' hands rested on a cardboard that covered a computer keyboard, leaving five windows open for the space bar and four response keys (see Figure 4, lower panel). Left (right) hand responses were given by pressing the "Y" or the "A" ("-" or "Ä") button on the keyboard with the index or the middle finger, respectively. Note that these keys are located on the German keyboard above the ALT and ALT Gr keys. Keys for the middle finger are located above and at a greater extent than the keys for the index finger. These response keys were selected to allow the participants a natural and comfortable hand position (Figure 4).

The stimuli were presented as white-on-black images. Eight uppercase letters served as target stimuli. For each of the four possible responses, two uppercase letter stimuli served as targets (see Figure 4). The pairs S and K, D and N, E and U, and C and H were mapped onto a response of the left middle finger, the left index finger, the right index finger, and the right middle finger, respectively. Targets were presented in the center of the monitor for $200 \mathrm{msec}$, subtending about $0.7^{\circ}$ of visual angle. The cues are illustrated in Figure 4, upper panel. Hand cues consisted of left- and right-pointing arrows subtending $1.0^{\circ}$ of visual angle. For separated cues, the finger cues were the German words Zeigefinger, Mittelfinger, and Beide Finger (English, index finger, middle finger, and both fingers), subtending between $2.3^{\circ}$ and $2.5^{\circ}$ of visual angle. The word and the arrow cues appeared about $0.3^{\circ}$ of visual angle above and below fixation, respectively. A double arrow pointing from left to right served as a neutral hand cue. Integrated cues consisted of two arrows. In addition to a hand arrow, the finger arrow pointed from fixation up or down, indicating the middle or the index finger, respectively. Finger arrows subtended $1.1^{\circ}$ of visual angle. Finger and hand arrows' tails were located at the fixation cross. On neutral trials, the cue of the nonneutral dimension was presented alone. However, in trials with both neutral hand and neutral finger cues, two double arrows were presented pointing up and down and from left to right (see Figure 4). In the case of a response error, the German word falsch (English, wrong) was presented in orange centered on the monitor for $1,000 \mathrm{msec}$, subtending about $4.2^{\circ}$ of visual angle.

\section{Design}

The design differed from that of Experiment 1 in two respects. First, within-subjects factors of hand cue and finger cue were used. Second, one practice session was followed by two experimental sessions, each including 70 warm-up trials and two blocks with 200 experimental trials comprising 32 trials in each of the four most infrequent conditions.

\section{Procedure and Statistical Analysis}

The procedure was identical to that in Experiment 1, except that the computer monitored for a response within 1,200 $\mathrm{msec}$ after target onset and the rest after error feedback lasted 1,500 msec. The sequence of events is depicted in Figure 5. Statistical analysis was identical to that of Experiment 1.

\section{Results}

\section{Separated Cues}

RT. The effect of hand cue was significant, with means of 563, 606, and $644 \mathrm{msec}$ for valid, neutral, and invalid hand cues, respectively $\left[F(2,18)=41.5, M S_{\mathrm{e}}=\right.$ $1,189, p<.001]$. Finger cue had a significant effect on RT, with means of 561, 604, and $649 \mathrm{msec}$ for valid, neutral, and invalid finger cues, respectively $[F(2,18)=$ $\left.24.8, M S_{\mathrm{e}}=2,323, p=.001\right]$. As compared with neutral cue conditions, both hand cue and finger cue produced significant costs and benefits $(p<.05)$. The interaction of hand cue and finger cue was significant $[F(4,36)=$ 3.6, $\left.M S_{\mathrm{e}}=604.1, p=.045\right]$. However, this interaction was due to the neutral cue conditions, because the interaction was absent when neutral conditions were excluded $\left[F(1,9)=0.4, M S_{\mathrm{e}}=518.3, p=.556\right]$. Mean RTs for each of the nine combinations of hand cue and finger cue are given in Figure 6A.

Errors. Errors occurred on $5.0 \%$ of the trials. Mean error rates were significantly affected by hand cue, with means of $3.1 \%, 3.8 \%$, and $8.2 \%$ for valid, neutral, and invalid hand cues, respectively $\left[F(2,18)=20.3, M S_{\mathrm{e}}=\right.$ $0.032, p<.001]$. As compared with the neutral cue condition, hand cue produced significant costs $(p<.05)$. Figure 6A shows mean error rates.

\section{Integrated Cues}

RT. Hand cue affected RT significantly, with means of 572, 623, and $663 \mathrm{msec}$ for valid, neutral, and invalid hand cues, respectively $\left[F(2,18)=33.3, M S_{\mathrm{e}}=1,844, p<\right.$ $.001]$. In addition, finger cue had a significant effect on RT, with means of 586, 625, and $648 \mathrm{msec}$ for valid, neutral, and invalid finger cues, respectively $[F(2,18)=$ $\left.15.8, M S_{\mathrm{e}}=1,832, p=.001\right]$. As compared with neutral cue conditions, finger cue prolonged RT significantly in 


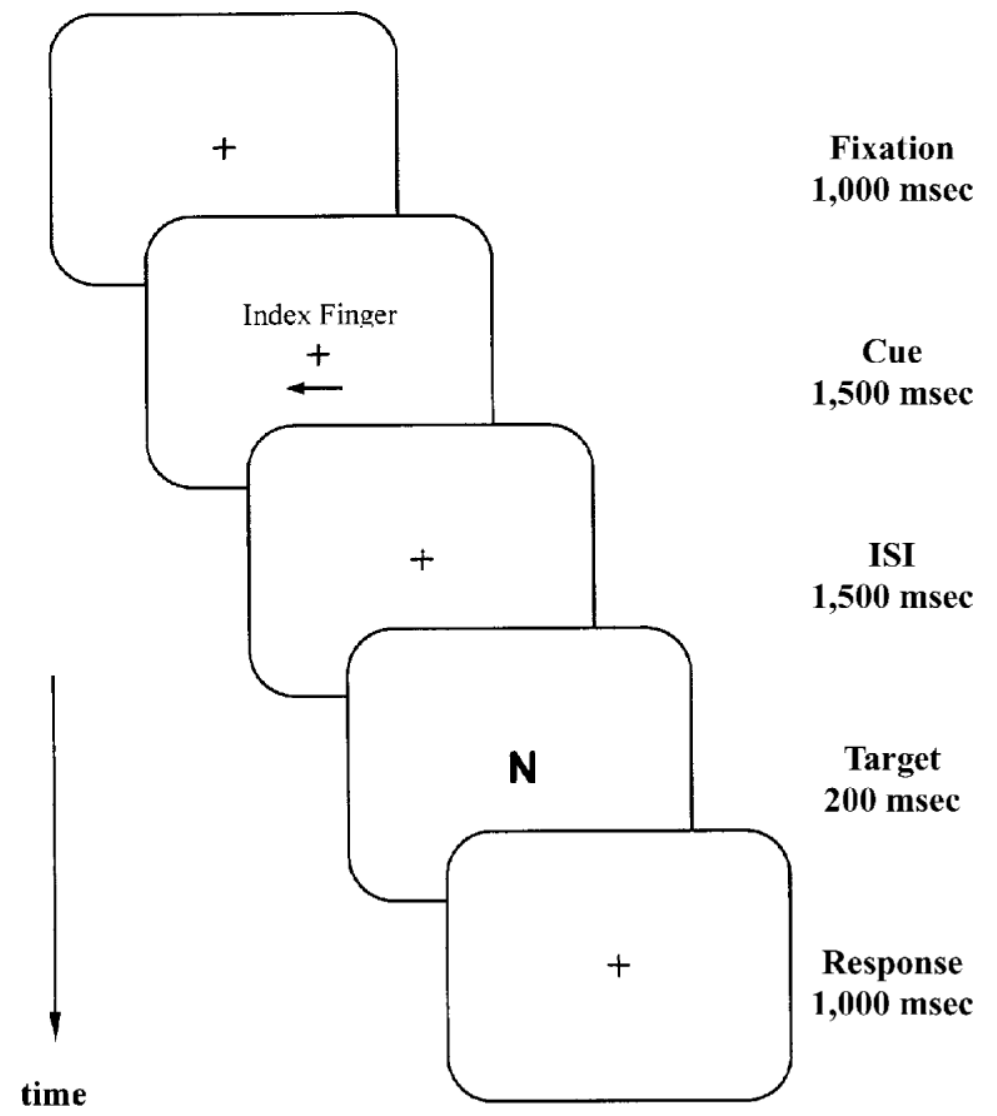

Figure 5. Schematic diagram of the sequence of events in Experiment 2. In this example of a trial with valid finger and valid hand cuing, type of cue is arrow-and-word.

invalid trials, but hand cue produced both significant costs and benefits $(p<.05)$. The interaction of hand cue and finger cue was significant $\left[F(4,36)=8.8, M S_{\mathrm{e}}=\right.$ $828.7, p=.005]$. To see whether the interaction results from neutral cue conditions, an analysis without trials from neutral cue conditions was conducted, which confirmed the former analysis, including the significant interaction $\left[F(1,9)=11.0, M S_{\mathrm{e}}=2,249, p=.009\right]$. Mean RTs are given in Figure 6B.

Errors. On $3.4 \%$ of the trials, the participants made errors. However, mean error rates did not vary with hand cue or finger cue factors or with their interaction. Mean error rates for each of the nine conditions are given in Figure 6B.

\section{Comparing Groups With Different Types of Cues}

RT. Both hand cue and finger cue had significant effects on RT $\left[F(2,36)=72.9, M S_{\mathrm{e}}=1,517, p<.001\right.$, and $F(2,36)=40.2, M S_{\mathrm{e}}=2,078, p<.001$, respectively]. The interaction of hand cue and finger cue was significant $\left[F(4,72)=9.1, M S_{\mathrm{e}}=716.4, p<.001\right]$. Most important, the interaction of type of cue, hand cue, and finger cue was significant $[F(4,72)=4.1, p=.015]$. These effects were not due to neutral cue conditions, because the analysis without data from neutral cue trials yielded the same pattern of effects and confirmed especially the interaction of type of cue, hand cue, and finger cue $[F(1,18)=$ $\left.7.4, M S_{\mathrm{e}}=1,383, p=.014\right]$. No other effect reached significance.

Errors. The analysis of both groups yielded a significant effect of hand cue and a significantinteraction of hand cue and type of cue $\left[F(2,36)=18.0, M S_{\mathrm{e}}=0.033, p<.001\right.$, and $F(2,36)=4.3, p=.024$, respectively], indicating that hand-cuing effects on error rates were larger in the group with separated cues than in the group with integrated cues (see Figure 6). No other effect reached significance.

Discussion. In both groups of participants, finger cues and hand cues affected RT, with costs and benefits of invalid and valid cues, respectively. Type of cue determined how hand cue and finger cue acted together. With integrated cues, the effect of finger cue on RT was reduced in trials with invalid hand cues. To the contrary, with separated cues, finger cue effects on RT were about the same with valid and invalid response cues. Thus, Experiment 2 replicated and extended the findings from Experiment 1 in a radically different task. 
A $\quad$ Index finger
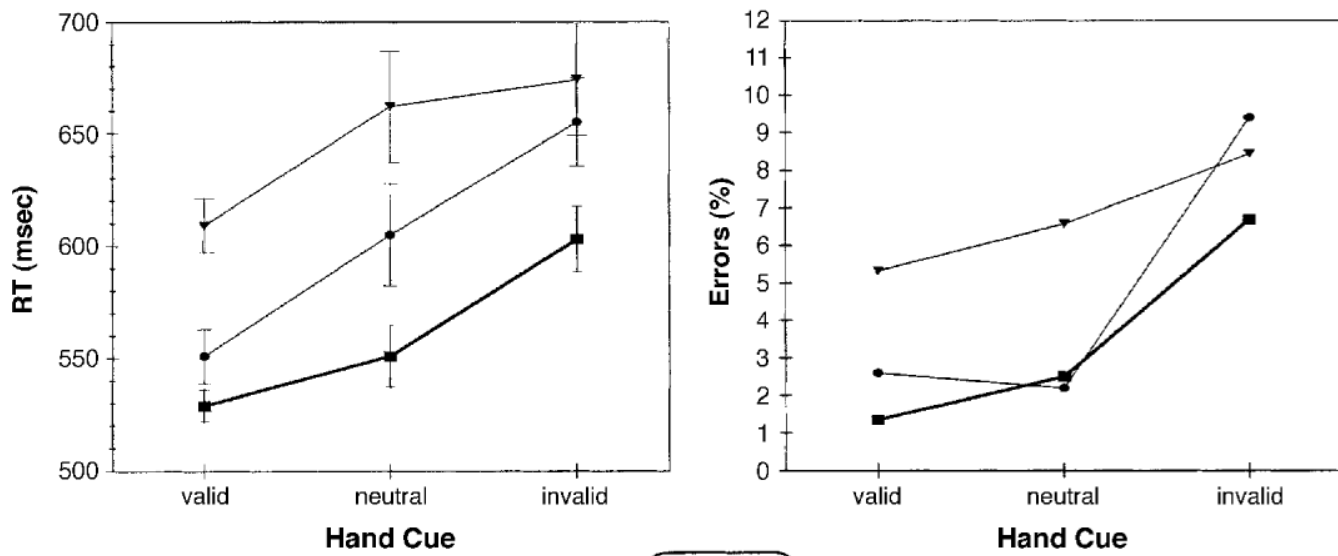

Feature

Cue

invalid

-

valid

valid

B
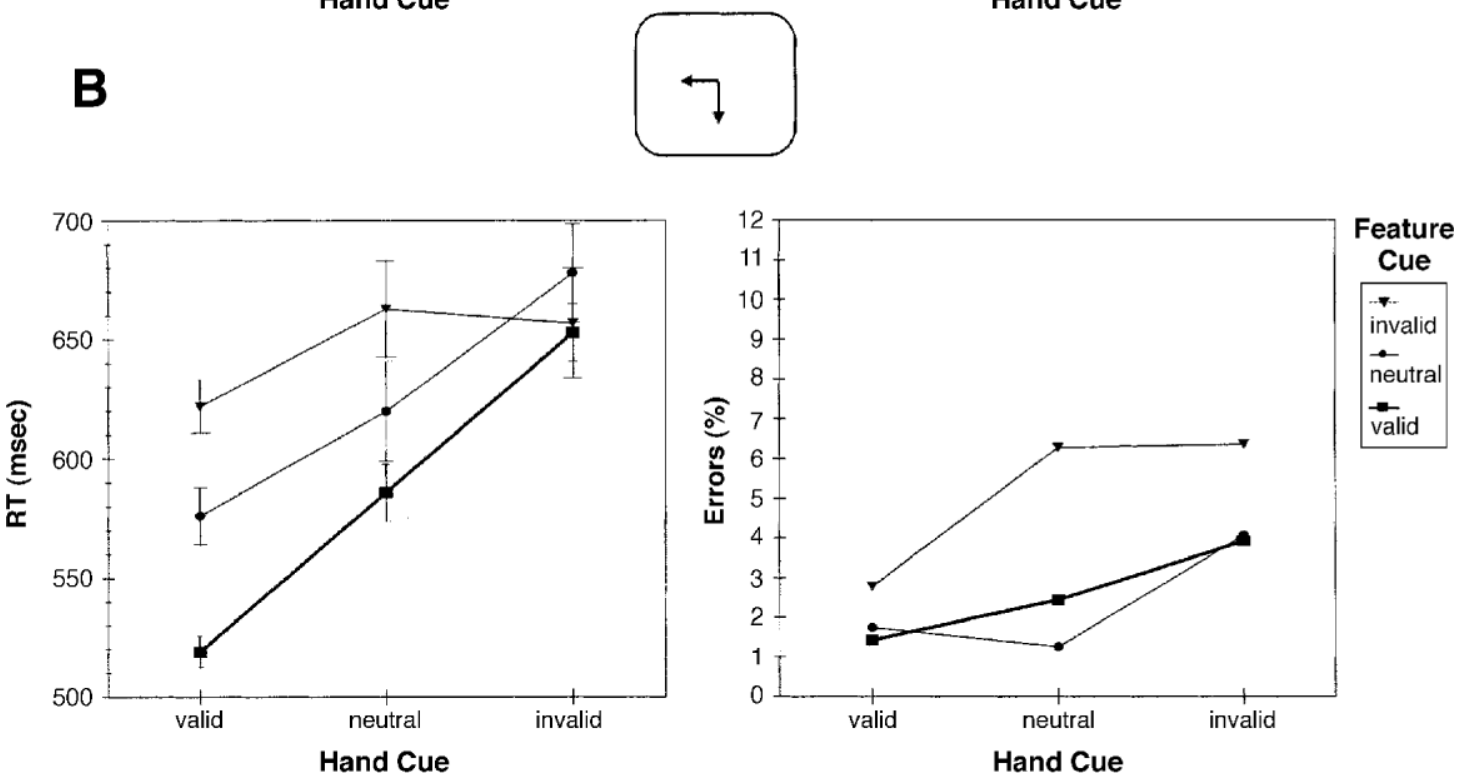

Figure 6. Reaction times (RTs) and error rates of combined expectancies of response hand and response finger in Experiment 2. (A) Separated cues consisting of a word and an arrow. (B) Integrated cues consisting of two arrows. Examples of type of cue are given in the monitor sketch between the left and the right panels. Error bars show twice the mean standard error of RTs of single trials for each condition, calculated for each participant and averaged across participants.

Experiment 2 used a cuing paradigm that extended previous studies on motor control of finger movements (Miller, 1982, 1985, 1988; Reeve \& Proctor, 1984, 1985). When the effects of valid and invalid cues for finger or hand components of a forthcoming movement were compared, the results indicate that both components can be specified in variable order if the precues consist of a word and an arrow. This finding is in line with the findings of Reeve and Proctor (1984) showing the same benefit with valid hand precues as with valid finger precues when the cue-target interval exceeded 1,500 msec. Thus, when participants have enough time to evaluate precues, finger movements are specified according to the general rule of specification with variable order (Rosenbaum, 1983). Beyond this, the present findings show that specification of finger and hand components are not independent when integrated cues are used. On the background of Experiment 1, this finding extends the perspective of motor control theory, suggesting that type of cue modulates the interaction of any two expectancies across a wide range of experimental tasks in the same way, due to a general principle that governs the combination of ex- 
pectancies. However, before this issue can be settled, two alternative ideas regarding the cuing effects in Experiment 2 have to be considered.

First, the findings could possibly be the result of two informative arrows increasing the probability of selecting the particular response indicated by the integrated cue, whereas the remaining three alternative responses are given less priority for selection. From this, it would follow that each of the three alternative responses should be delayed, on the average, to the same degree. However, this hypothesis is not supported by the data, because on trials with invalid finger cues the effect of hand cue (valid vs. invalid) was significant both on mean RT $\left[F(1,18)=12.3, M S_{\mathrm{e}}=390.4, p=.001\right]$ and on the mean within-subjects standard error of RT $[F(1,18)=15.0$, $\left.M S_{\mathrm{e}}=26.2, p<.001\right]$. Both mean RT and mean standard error were reduced in trials with valid hand cues (see Figure 6B). Therefore, the findings cannot be explained by a simple strategy such as preparing only one of the four responses when cues are integrated.

Second, the present effect of type of cue could possibly result from a stimulus-response compatibility effect, because separated cues are less compatible with the response, as compared with integrated cues. According to this view, the effects of separated cues combined additively because these cues are incompatible and, therefore, lead to serial specification; integrated cues, however, are compatible cues that affect response selection in such a way that RT does not depend on what movement component has to be specified, but simply on the number of unspecified response alternatives (see Goodman \& Kelso, 1980).

This account faces four problems, however. In the first place, this kind of compatibility effect is not a robust phenomenon (see Leuthold, Sommer, \& Ulrich, 1996). Second, Goodman and Kelso (1980) found the compatibility effect in an experiment that varied cue-response compatibility together with target-response compatibility. In the present experiment, targets were always incompatible letters, and only cue-response compatibility varied with type of cue. However, because the participants had plenty of time to process the cues before the target required the response, it seems very unlikely that differences in cue-response translation produced the present results. Third, electrophysiological studies suggest that precuing of movement components affects the motor system instead of stimulus-response translation processes (de Jong, Wierda, Mulder, \& Mulder, 1988; Fu et al., 1995; Leuthold et al., 1996; Osman, Moore, \& Ulrich, 1995; Requin et al., 1993; Ulrich, Moore, \& Osman, 1993). Leuthold and colleagues showed that both compatible and incompatible cues can affect the motor system in a component-specific way, suggesting that the effect of type of cue in Experiment 2 is not restricted to levels of stimulus-response translations. Finally, the combination of perceptual expectancies in Experiment 1 was affected by type of cue in a way similar to that for the combination of response-related expectancies in Ex- periment 2, although the cues did not differ regarding stimulus-response compatibility in Experiment 1. To avoid having two different accounts for the similar findings in both of the experiments of the present study, it is more parsimonious to account for the effect of type of cue in terms of a general principle that governs these and other combinations of expectancies.

This general principle is expressed by the adjusted expectancy model, which has been proposed as an account for previous findings of interacting expectancies (Mattler, in press). Experiment 2 demonstrates that finger cuing and hand cuing interact when integrated cues are used but that cuing effects remain independent with separated cues. This finding suggests that combined responserelated expectancies are governed by the same rules as those that operate on the combination of spatial cuing with feature cuing (Experiment 1) and on the combination of other perceptual expectancies with response cuing (Mattler, in press). According to the adjusted expectancy model, the interaction of combined expectancies results from crosstalk between early and late levels of expectancy effects. Because the model assumes that the degree of crosstalk is a function of type of cue, the results of Experiment 2 confirm the adjusted expectancy model. Furthermore, these results extend the range of the model, because they show that perceptual expectancies are not necessary for expectancy interaction.

The model is consistent with the general rule of serial specification of movement components in variable order, because it assumes that early and late levels of processing are organized sequentially. However, the present results contribute to motor control theory, because they show that an interaction of cuing effects can result from the adjustment of expectancies operating on top of sequential processing. In other words, even if movement components are specified serially with variable order, performance measures do not show additive effects when expectancy effects are adjusted as the model proposes. Therefore, an interaction of cuing effects does not by itself contradict the rule that movement components are specified serially with variable order.

\section{GENERAL DISCUSSION}

The present study extends previous work on combined expectancy effects by combining two pieces of advance knowledge, regarding either two perceptual expectancies or two response-related expectancies. Despite the fact that fundamentally different expectancies were induced in the two experiments, similar cuing effects were found, and their interaction was modulated similarly by type of cue: Expectancies interacted with integrated cues to a greater extent than with separated cues. This pattern of result replicates the findings from previous experiments (Mattler, in press). These comparable findings within perceptual cuing, within motor cuing, and across perceptual and motor cuing suggest a general principle that governs the combination of expectancies across a wide 
range of cuing effects. According to this principle, implicit information provided by the type of cue combination modulates the interaction of expectancies. Most important, this principle provides another instance that serves to unify the research on attention and motor preparation, extending previous findings that have shown similar effects of masked stimuli in perceptual and motor priming (Mattler, 2003). In the following, I want to comment on the modulatory effect of type of cue and on a theoretical account of interacting expectancies in terms of an adjusted expectancy model.

\section{Modulation by Type of Cue}

The present results show that combined expectancies interact to a greater extent when cues consist of integrated information, as compared with separated parts of information. To what extent can we ignore all the other differences between cues, besides being integrated and separated? Most other differences between cues have to do with the perceptual processing required to obtain the information necessary to induce the proper expectancy. For instance, separated cues provide two objects for spatial attention to focus on, whereas integrated cues provide only one; extracting spatial information from an arrow cue requires processes that are different from those required to process the location of a word (see Experiment 1); integrated cues that consist of two physically connected arrows require different processing than do integrated cues that consist of a word located at a specific spatial position. However, to evaluate any of these and other differences between cues, it has to be noted that the cues were presented for $1,500 \mathrm{msec}$, followed by another $1,500 \mathrm{msec}$ prior to target processing. Because any kind of stimulus processing should by completed $3 \mathrm{sec}$ after stimulus onset, it seems unlikely that any of the differences between cues having to do with perceptual processing can account for the differences found with integrated cues, as compared with separated cues. To the contrary, it seems reasonable that the effect of type of cue results from the different consequences that follow from the processing of separated and integrated cues.

Type of cue might have been a crucial factor in other studies too. Expectancy interaction was found by Klein and colleagues when the expectancy of one stimulus alternative was induced by increasing the general frequency of this stimulus alternative, as compared with the other, throughout the experiment. Spatial location, however, was cued in a trial-by-trial fashion by an arrow (Klein, 1980, 1994; Klein \& Hansen, 1987, 1990). To integrate this finding into the present perspective, we just have to assume that expectancies were induced on each trial by the single stimulus that had the same effects as integrated cues. In other words, advance information was not given by two distinct pieces of information in these experiments, resulting in the implicit information that the expectancies were related. Kingstone (1992) found expectancy interaction with integrated cues con- sisting of a letter-digit pair indicating temporal and form information and with cues consisting of colored digits. All of these experiments obtained expectancy interactions, and consistent with the present hypothesis, cue combinations can be analyzed as integrated cues. Additive combinations of expectancy effects were found by Kingstone (1992, Experiment 2), with separated cues consisting of an arrow indicating the likely stimulus location and a digit indicating the likely target form. Similarly, additive expectancy effects were found in a series of experiments on combined perceptual and motor-related expectancies (Mattler, in press) when cues consisted of a word and an arrow.

The literature has reported the results of three experiments that seem to conflict with the present analysis. Lambert and Hockey (1986) found additive effects of spatial cuing and form cuing in their Experiment 1, although they used integrated cues consisting of a form superimposed on a line. As was mentioned above, however, this result of Lambert and Hockey is based on median RTs, which might as well have eliminated the expectancy interaction. Two experiments of Kingstone (1992, Experiments 1 and 3) combined spatial cuing with stimulus form cuing and showed expectancy interactions even though separated cues were used, consisting of an arrow and a digit. However, these deviant results suffer from extremely low numbers of replications in the most infrequent conditions, with 4 and 14 trials in Experiments 1 and 3, respectively. Furthermore, in the similar Experiment 2 of Kingstone, cuing effects did not interact when the same separated cues were used. Thus, the majority of findings in the literature are in line with the present view, and conflicting findings result from experiments that suffer from methodological and experimental flaws.

Taken together, the previous findings are consistent with the view that the interaction of expectancies is modulated by type of cue. Expectancy interaction is found with integrated cues consisting either of two simple forms, such as two arrows, a letter-digit pair, or a colored digit, or of a single word that provides both pieces of information. Additive expectancy effects occur with separated cues consisting of two clearly separated pieces of information provided, for instance, by an arrow and a word or by an arrow and a digit.

\section{Adjusted Expectancy Model}

The adjusted expectancy model assumes that expectancy interaction occurs when disconfirmed earlylevel expectancies lead to an adjustment of expectancies at late levels of processing. Four assumptions of the model shall be considered in more detail: temporal hierarchical processing, on-line adjustment, a general principle, and a network of processing. First, the model assumes a temporal hierarchical relation between those levels that are affected by expectancies. This requirement was satisfied rather naturally when spatial cuing was combined with response cuing (Mattler, in press). In order to explain the present findings within perceptual 
cuing and within motor cuing with this model, cues have to affect processes that finish in a sequential fashion. For the combination of feature cuing and spatial cuing in Experiment 1 , theories of visual search assume a hierarchical relation. For instance, according to Guided Search, stimulus features are processed at early levels of preattentive processing, whereas spatial cuing affects the spotlight of attention at later levels of processing. For the combination of hand cuing and finger cuing, a hierarchical relation is consistent with the view that specification of movement components is serial (Rosenbaum, 1983). Furthermore, the basic idea of the model is consistent with a variable order of processing as long as there is a temporal hierarchical relation between processes. In other words, to adjust the activation of representations at one level of processing, a signal has to be provided by faster processing at another level, telling whether the preactivation there was correct or not. This basic idea is satisfied when processing at Level $\mathrm{A}$ is fastest in one trial but processing at Level B is faster in the other trial. To sum up, the model assumes a temporal hierarchical relation between levels of processing, and the basic idea allows a variable order of processing.

Second, the adjusted expectancy model assumes that on-line adjustment happens in the course of a single trial. This might seem very quick, because cuing studies in which the interval between cue and target presentation was varied show that several hundreds of milliseconds are required for cuing effects to reach their full size. On the other hand, however, in motor priming, the effect of primes on RT increases with the interval between prime and target stimuli by almost every millisecond in a oneto-one manner (Mattler, 2003). Note, however, that it is troublesome to deduce the speed of on-line adjustment of activation, as assumed by the model, directly from the effect of cue-target intervals on cuing effects, because the time necessary to change an activation does not have to be equal to the time to finish processing in a network or to the time necessary to elicit a response. To the contrary, small changes in activation might have relatively large effects on RT. On this background, the assumption of on-line adjustment is plausible and not in conflict with empirical findings.

Third, the adjusted expectancy model applies the same general principle to any combination of expectancies. The model assumes that the activation of representations and the adjustment of activations follow the same principle regardless of what event is related to the representation. According to the model, expectancy effects consist of the selective activation of specific representations that compete in a network of alternative representations. This principle is assumed to operate in any network consisting of perceptual, cognitive, or motor representations. Furthermore, it is assumed that a mechanism of adjustment is triggered by early processing and that this mechanism affects the processing at later levels. This assumption of a general principle is confirmed by comparing perceptual and motor cuing in the present study: Similar combined expectancy effects were affected in the same way by type of cue, although different expectancies were combined in the two experiments.

Finally, the adjusted expectancy model assumes three instances that together produce the effects of combined expectancies. Basically, the model distinguishes between central control processes and peripheral data-processing units (see Posner \& Raichle, 1994). The model assumes that central processes interpret the cues and control their effects on both data-processing units that are subject to one of the two expectancies. Whereas central processes are shared by different tasks involving combined expectancies, the data-processing units are assumed to differ with the particular events that are expected in a given task. An important assumption of the model is that dataprocessing units operate in the same way in cuing tasks despite anatomical and functional differences between tasks. These assumptions are consistent with neurophysiological findings that emphasize specific locations of advance knowledge effects and with an increasing number of findings showing that specific networks of brain structures are involved in any experimental task (e.g., Casey et al., 2000; Deiber, Ibanez, Sadato, \& Hallett, 1996). For instance, in spatial cuing and visual search, the same cortical network seems to be employed, including the frontal cortex and specific structures of the parietal or the temporal cortex (e.g., Corbetta \& Shulman, 1998; Luck, 1998), and cuing effects at specific locations in the extrastriate cortex thus most likely result from a top-down bias caused by frontal and parietal control structures (e.g., Desimone \& Duncan, 1995). These neurophysiological findings correspond to the framework of the adjusted expectancy model, which assumes that shared, as well as specific, cortical structures play their part in perceptual and motor cuing tasks.

Further support for the model is provided by the successful account of the data of the present experiments. Because the model is expressed in mathematical terms, RTs of single trials could be determined in Monte Carlo simulations using estimated parameters of single participants. These analyses revealed that the model accounts reasonably well for the means and the distributions of the RTs of individual participants in both of the present experiments. Further support for the model is expected from imaging studies that localize cuing effects.

\section{Conclusion}

The present research extends previous findings with combined expectancies by demonstrating comparable effects when two perceptual expectancies are combined as when two response-related expectancies are combined. Together with previous experiments, these results suggest that similar effects occur regardless of what specific expectancies are combined. The results confirm the hypothesis that type of cue modulates how expectancies are combined. The adjusted expectancy model expresses a general principle to account for this broad range of combined expectancy effects. 


\section{REFERENCES}

Briand, K. A., \& KLein, R. M. (1987). Is Posner's "beam" the same as Treisman's "glue"? On the relation between visual orienting and feature integration theory. Journal of Experimental Psychology: Human Perception \& Performance, 13, 228-241.

Casey, B. J., Thomas, K. M., Welsh, T. F., Badgaiyan, R. D., Eccard, C. H., Jennings, J. R., \& Crone, E. A. (2000). Dissociation of response conflict, attentional selection, and expectancy with functional magnetic resonance imaging. Proceedings of the National Academy of Sciences, 97, 8728-8733.

Corbetta, M., \& Shulman, G. L. (1998). Human cortical mechanisms of visual attention during orienting and search. Philosophical Transactions of the Royal Society of London: Series B, 353, 1353-1362.

Deiber, M. P., Ibanez, V., Sadato, N., \& Hallett, M. (1996). Cerebral structures participating in motor preparation in humans: A positron emission tomography study. Journal of Neurophysiology, 75, 233-247.

de Jong, R., Wierda, M., Mulder, G., \& Mulder, L. J. M. (1988). Use of partial stimulus information in response processing. Journal of Experimental Psychology: Human Perception \& Performance, 14, 682-692.

Desimone, R., \& Duncan, J. (1995). Neural mechanisms of selective visual attention. Annual Review of Neuroscience, 18, 193-222.

ERIKSEN, C. W., \& YEH, Y. Y. (1985). Allocation of attention in the visual field. Journal of Experimental Psychology: Human Perception \& Performance, 11, 583-597.

Found, A., \& Müller, H. J. (1996). Searching for unknown feature targets on more than one dimension: Investigating a "dimensionweighting" account. Perception \& Psychophysics, 58, 88-101.

Fu, Q. G., Flament, J. D., Coltz, J. D., \& Ebner, T. J. (1995). Temporal encoding of movement kinematics in the discharge of primate primary motor and premotor neurons. Journal of Neurophysiology, 73, 836-854.

Goodman, D., \& Kelso, J. A. S. (1980). Are movements prepared in parts? Not under compatible (naturalized) conditions. Journal of Experimental Psychology: General, 109, 475-495.

Humphreys, G. W. (1981). Flexibility of attention between stimulus dimensions. Perception \& Psychophysics, 30, 291-302.

KASTNER, S., \& UNGERLEIDER, L. G. (2000). Mechanisms of visual attention in the human cortex. Annual Review of Neuroscience, 23, 315-341.

KIngstone, A. (1992). Combining expectancies. Quarterly Journal of Experimental Psychology, 44A, 69-104.

Kingstone, A., \& Klein, R. (1991). Combining shape and position expectancies: Hierarchical processing and selective inhibition. Journal of Experimental Psychology: Human Perception \& Performance, 17, 512-519.

KLEIN, R. [M.] (1980). Does oculomotor readiness mediate cognitive control of visual attention? In R. S. Nickerson (Ed.), Attention and performance VIII (pp. 259-276). Hillsdale, NJ: Erlbaum.

KLEIN, R. M. (1994). Perceptual-motor expectancies interact with covert visual orienting under conditions of endogenous but not exogenous control. Canadian Journal of Experimental Psychology, 48, 167-181.

KLEIN, R. M. (2000). Inhibition of return. Trends in Cognitive Sciences, 4, 138-147.

KLEIN, R. [M.], \& HANSEN, E. (1987). Spotlight failure in covert orienting. Bulletin of the Psychonomic Society, 25, 447-450.

KLein, R. [M.], \& Hansen, E. (1990). Chronometric analysis of apparent spotlight failure in endogenous visual orienting. Journal of Experimental Psychology: Human Perception \& Performance, 16, 790-801.

LAMBERT, A. (1987). Expecting different categories at different locations and spatial selective attention. Quarterly Journal of Experimental Psychology, 39A, 61-76.

Lambert, A., \& Hockey, R. (1986). Selective attention and performance with a multidimensional visual display. Journal of Experimental Psychology: Human Perception \& Performance, 12, 484-495.

Leuthold, H., Sommer, W., \& UlRich, R. (1996). Partial advance information and response preparation: Inferences from the lateralized readiness potential. Journal of Experimental Psychology: General, 125, 307-323.
LuCK, S. J. (1998). Neurophysiology of selective attention. In H. Pashler (Ed.), Attention (pp. 257-296). Hove, U.K.: Psychological Press.

Mattler, U. (2003). Priming of mental operations by masked stimuli. Perception \& Psychophysics, 65, 167-187.

MattLer, U. (in press). Combined expectancy effects are modulated by the relation between expectancy-cues. Quarterly Journal of Experimental Psychology.

Milán, E. G., \& Tornay, F. J. (2001). Spotlight failure effect in exogenous orienting. Acta Psychologica, 108, 209-218.

Miller, J. O. (1982). Discrete versus continuous stage models of human information processing: In search of partial output. Journal of Experimental Psychology: Human Perception \& Performance, 8, 273-296.

Miller,J. O. (1985). A hand advantage in preparation of simple keypress responses: Reply to Reeve and Proctor (1984). Journal of Experimental Psychology: Human Perception \& Performance, 11, 221-233.

Miller, J. (1987). Evidence of preliminary response preparation from a divided attention task. Journal of Experimental Psychology: Human Perception \& Performance, 13, 425-434.

Miller, J. (1988). Response-compatibility effects in focused-attention tasks: A same-hand advantage in response activation. Perception \& Psychophysics, 43, 83-89.

MotTER, B. C. (1994). Neural correlates of attentive selection for color or luminance in extrastriate area V4. Journal of Neuroscience, 14, 2178-2189.

Murphy, F. C., \& KLein, R. M. (1998). The effects of nicotine on spatial and non-spatial expectancies in a covert orienting task. Neuropsychologia, 36, 1103-1114.

NeELY, J. H. (1977). Semantic priming and retrieval from lexical memory: Roles of inhibitionless spreading of activation and limited-capacity attention. Journal of Experimental Psychology: General, 106, 226254.

Osman, A., Moore, C. M., \& Ulrich, R. (1995). Bisecting RT with lateralized readiness potentials: Precue effects after LRP onset. Acta Psychologica, 90, 111-127.

Posner, M. I., \& Raichle, M. E. (1994). Images of mind. New York: Scientific American Library.

Posner, M. I., \& SNYDER, C. R. R. (1975). Attention and cognitive control. In R. L. Solso (Ed.), Information processing and cognition: The Loyola Symposium (pp. 55-85). Hillsdale, NJ: Erlbaum.

Posner, M. I., SNyder, C. R. R., \& Davidson, B. J. (1980). Attention and the detection of signals. Journal of Experimental Psychology: General, 109, 160-174.

Rabiitt, P. M. A. (1966). Errors and error correction in choiceresponse tasks. Journal of Experimental Psychology, 71, 264-272.

Reeve, T. G., \& Proctor, R. W. (1984). On the advance preparation of discrete finger responses. Journal of Experimental Psychology: Human Perception \& Performance, 10, 541-553.

Reeve, T. G., \& Proctor, R. W. (1985). Nonmotoric translation processes in the preparation of discrete finger responses: A rebuttal of Miller's (1985) analysis. Journal of Experimental Psychology: Human Perception \& Performance, 11, 234-241.

Requin, J., Riehle, A., \& Seal, J. (1993). Neuronal networks for movement preparation. In D. E. Meyer \& S. Kornblum (Eds.), Attention and performance XIV: Synergies in experimental psychology, artificial intelligence, and cognitive neuroscience (pp. 745-769). Cambridge, MA: MIT Press.

Rosenbaum, D. A. (1980). Human movement initiation: Specification of arm, direction, and extent. Journal of Experimental Psychology: General, 109, 444-474.

Rosenbaum, D. A. (1983). The movement precuing technique: Assumptions, applications, and extensions. In R. A. Magill (Ed.), Memory and control of action (pp. 231-274). Amsterdam: North-Holland.

Rosenbaum, D. A., \& Kornblum, S. (1982). A priming method for investigating the selection of motor responses. Acta Psychologica, 51, 223-243.

Spence, C., \& Driver, J. (1997). On measuring selective attention to an expected sensory modality. Perception \& Psychophysics, 59, 389403.

Treisman, A. M., \& Gelade, G. (1980). A feature integration theory of attention. Cognitive Psychology, 12, 97-136.

Treisman, A. [M.], \& Sato, S. (1990). Conjunction search revisited. 
Journal of Experimental Psychology: Human Perception \& Performance, 16, 459-478.

Ulrich, R., Giray, M., \& SchÄFfER, R. (1990). Is it possible to prepare the second component of a movement before the first one? Journal of Motor Behavior, 22, 125-148.

Ulrich, R., Moore, C., \& Osman, A. (1993). Lateralisiertes Bereitschaftpotential und Reaktionsgeschwindigkeit bei partieller Vorinformation eines Handlungsparameters [Lateralized readiness potential and reaction times: The effect of partial response cues]. Zeitschrift für Experimentelle und Angewandte Psychologie, 40, 310325.

Wolfe, J. M. (1994). Guided Search 2.0: A revised model of visual search. Psychonomic Bulletin \& Review, 1, 202-238.

Wolfe, J. M. (1996). Extending guided search: Why guided search needs a preattentive "item map." In A. F. Kramer, M. G. H. Coles, \& G. D. Logan (Eds.), Converging operations in the study of visual selective attention (pp. 247-270). Washington, DC: American Psychological Association.

Wolfe, J. M. (1998). Visual search. In H. Pashler (Ed.), Attention (pp. 13-73). Hove, U.K.: Psychology Press.

Wolfe, J. M., Cave, K. R., \& Franzen, S. L. (1989). Guided Search: An alternative to the feature integration model for visual search. Journal of Experimental Psychology: Human Perception \& Performance, 15, 419-433.

\section{NOTES}

1. Note that the term cuing in this article refers to the technique of giving cues that are valid most of the time and invalid on some trials. However, in research of motor control, this technique is often called priming, and the term precuing often refers to giving advance informa- tion that is always valid but incomplete on some trials (e.g., Rosenbaum \& Kornblum, 1982).

2. Note that perceptual cuing, like feature cuing, possibly includes some preparation of stimulus-response mappings. This is a general problem of the perceptual cuing used to study attention (e.g., modality cuing, feature cuing). In Experiment 1, the participants were instructed to use cues to prepare for the perception of color or tilted lines. In other experiments, the participants consistently reported using cues to prepare for stimuli when given a comparable instruction. Neurophysiological studies show modified processing in perceptual systems when stimulus dimensions such as movement, location, objects, or simple features such as color are attended (Motter, 1994; for an overview, see Kastner $\&$ Ungerleider, 2000). Therefore, feature cuing was considered perceptual cuing, in line with the traditional literature on visual attention.

3 . Note that this pattern of results rules out a number of simple accounts of combined expectancy effects that frequently come up when people consider these findings. For instance, if participants attend to only one cue at a time but vary which cue they attend to over trials, we would expect mean RTs similar to those found in trials in which only one cue was presented-namely, trials with a neutral cue-but larger variability. If participants attend only to the combination of valid cues, RTs in all other conditions should be slower than those in the valid condition, but these conditions should not differ. If participants switch strategies between trials, variability should be larger in trials with two cues, as compared with trials with one neutral cue that allows only one strategy. None of these predictions is supported by the data (see Figures 3 and 6). Therefore, a deeper analysis is required, such as that provided by the adjusted expectancy model.

(Manuscript received August 8, 2001; revision accepted for publication November 26, 2002.) 